\title{
Recent Evaluations of the Peer-Led Approach In Adolescent Sexual Health Education: A Systematic Review
}

\begin{abstract}
CONTEXT: Peer-led interventions have become a popular method of providing sexual health education to adolescents, but the efficacy of this approach and the methodological quality of recent trials have not been systematically reviewed.

METHODS: Electronic and hand searches were conducted to identify quasi-randomized and randomized controlled trials of peer-led adolescent sexual health education published from 1998 to 2005. Studies were eligible if they had an appropriate comparison group, provided preintervention and postintervention data, and reported all outcomes. Study results were summarized and, where appropriate, pooled; in addition, 10 aspects of studies' methodological quality were assessed.
\end{abstract}

RESULTS: Thirteen articles met the inclusion criteria. Pooled, adjusted results from seven trials that examined the effects of peer-led interventions on condom use at last sex found no overall benefit (odds ratio, 1.0). None of the three trials that assessed consistent condom use found a benefit. One study reported a reduced risk of chlamydia (0.2), but another found no impact on STI incidence. One study found that young women (but not young men) who received peer-led education were more likely than nonrecipients to have never had sex. Most interventions produced improvements in knowledge, attitudes and intentions. Only three studies fulfilled all 10 of the assessed quality criteria; two others met nine criteria.

CONCLUSIONS: Despite promising results in some trials, overall findings do not provide convincing evidence that peerled education improves sexual outcomes among adolescents. Future trials should build on the successful trials conducted to date and should strive to fulfill existing quality criteria.

International Family Planning Perspectives, 2008, 34(2):89-96
By Caron R. Kim
and Caroline Free

At the time this article was written, Caron R. Kim was a graduate student at the London School of Hygiene and Tropical Medicine, London. Caroline Free is a clinical lecturer at the London School of Hygiene and Tropical Medicine.
The sexual health of adolescents is a growing global public health issue. In developing countries, approximately $60 \%$ of new HIV infections occur among 15-24-year-olds, ${ }^{1}$ and a similar proportion of pregnancies and births to adolescents are unintended. ${ }^{2}$ In industrialized countries, the incidence of STIs among youth is increasing, ${ }^{3}$ and adolescent pregnancy is associated with poor social outcomes. ${ }^{4}$ These and other statistics have garnered adolescents attention as a group facing distinct issues.

Peer-led sexual health education is one means of addressing deficiencies in adolescent sexual health. Defined as the "teaching or sharing of information, values, and behaviors by members of similar age or status group," 5 peerled sexual health education has been developed on the basis of two observations. First, the health beliefs and habits formed during childhood and adolescence are carried into adulthood ${ }^{6}$ second, teenagers influence each other's attitudes and behavior. ${ }^{7}$ According to theory, peer educators may influence social behavior through their role as credible role models ${ }^{8}$ or as innovators. ${ }^{9}$ Moreover, peerled education may be an approach by which young people, through partnerships, can define and tackle their own health needs. ${ }^{9,10}$

Although several systematic reviews of adolescent sex- ual health interventions have been conducted, ${ }^{11,12}$ to our knowledge only one has focused on peer-delivered health promotion interventions. Harden and colleagues reviewed outcome and process evaluations of peer-led interventions (half of them involving sexual health) from randomized and quasi-randomized controlled trials published through September 1998. ${ }^{13}$

Harden and colleagues also appraised the methodology of the trials. In systematic reviews, methodological appraisals generally evaluate four areas of potential systematic bias: selection bias (differences in comparison groups), performance bias (differences in the care provided, apart from the intervention being evaluated), attrition bias (differences in withdrawals from trials) and detection bias (differences in outcome assessment). The rationale and content of criteria for the assessment of these types of bias are similar across reviews. ${ }^{12-17}$

While they were unable to reach robust conclusions regarding the effectiveness of peer-led interventions for young people, Harden and colleagues made a number of recommendations for the development and evaluation of such interventions. ${ }^{13}$ Although other guidelines for the development and evaluation of complex sexual health interventions have been devised, ${ }^{18}$ those of Harden and col- 
leagues are, as far as we are aware, the only ones specifically developed to guide the development and evaluation of peer-led interventions for young people. Their criteria for intervention development were informed by the following perspectives: that young people should actively participate in meeting their own health needs, ${ }^{19}$ that adolescents are not a homogenous group with uniform needs ${ }^{7}$ and that peer-led health promotion is best delivered in the context of wider sociocultural and economic health promotion strategies. ${ }^{20}$ In addition, the authors highlighted the importance of understanding the contribution that peer-led education can offer to wider health promotion strategies.

The criteria developed by Harden and colleagues were supported by findings from their review. First, echoing other authors, ${ }^{21}$ Harden and colleagues recommended that the health needs and views of the target group be assessed; they provided examples of how specific programs in their review used this information to tailor interventions to a particular context. Second, given the challenges that they identified within peer-led education interventionsincluding resource constraints, conflicting value systems and constraints on young people's autonomy (especially in schools)-they recommended that the specific boundaries of working partnerships with young people be established prior to project implementation, such that the roles of researchers and youth are clearly defined. Third, they noted that evidence suggests that the beneficiaries of peer-led sex education include the peer educators themselves; thus, they recommended the evaluation of the effects that peer education has on peer educators, and of reciprocal education, in which each member of a target population alternates between being an educator and a recipient. Fourth, they recommended that both quantitative and qualitative methods (and if possible, an integration of the two) be used to evaluate outcomes and processes. * Fifth, they concluded that the important characteristics of peer educators are unclear and recommended that, to help elucidate the matter, authors describe how peer educators were recruited and selected. Finally, they recommended that young peoples' views regarding the intervention, including negative views, be fully reported.

We conducted a systematic review and methodological appraisal of randomized and quasi-randomized controlled trials of peer-led sex education interventions. We also evaluated the extent to which Harden's recommendations for the development and evaluation of peer-led interventions have been addressed in studies published since 1998.

\footnotetext{
* Several authors have subsequently made similar recommendations for all complex interventions, arguing that while quantitative outcome evaluations are essential, process evaluations, which often use qualitative methods, can help elucidate why an intervention may be implemented and received differently in diverse settings, whether failure of an intervention is due primarily to a problem inherent to the intervention or to implementation failure, and how contextual factors can influence an intervention (source: reference 11).

tThe order of criteria in this article generally mirrors the order in which they appeared in the original guidelines and does not suggest any hierarchical level of importance.
}

\section{METHODS}

\section{Eligibility Criteria and Methodological Appraisal}

We examined all randomized and quasi-randomized controlled trials that evaluated interventions to promote adolescent sexual health using peer educators and that were published in 1998-2005. Any peer-led intervention intended to promote sexual health in any setting (e.g., health center, youth group, local extracurricular center, school) in high-, middle- or low-income countries was eligible. For inclusion in the review, studies had to have intervention and control groups, include adolescents aged 10-19 and be published in English.

In addition, studies were required to meet four methodological criteria: The studies had to include a control or comparison group whose social and demographic characteristics were similar to those of the intervention group, provide preintervention data for all groups, provide postintervention data for all groups and report all outcomes. Primary outcomes of interest were the occurrence of pregnancy or STIs, age at first sex, number and types of sexual partnerships, condom use and contraceptive use. Relevant secondary outcomes were measures of knowledge of sexual health or contraceptive services; behavioral intentions regarding sex or contraceptive use; and attitudes about sex, sexual health or contraceptives.

To identify relevant studies, we searched the following databases: EMBASE, ERIC, PubMed, International Bibliography of Social Science, PsycINFO, specialized bibliographic registers, DoPHER and the Cochrane Central Register of Controlled Trials. We used the search terms "peers," "adolescents," "education" and "health promotion" in combination with the search strategy detailed in the Cochrane Reviewers' Handbook. ${ }^{14}$ In addition, we contacted researchers, searched reference lists and hand searched all issues of the journals Health Education and Behavior and Health Education Research published in 19982005. The electronic records were scanned to identify potentially eligible studies. Because of resource constraints, we omitted unpublished works.

Given the similarity among existing guidelines for the methodological appraisal of randomized and quasirandomized controlled trials, ${ }^{12,14-17}$ we used the criteria developed by the Evidence for Policy and Practice Information and Coordinating Centre, ${ }^{15}$ with additional criteria based on the Cochrane review guidelines. ${ }^{14}$ For each study, we determined whether the authors provided a clear statement of aims, whether the description of the study design provided sufficient detail to allow replication, whether there was a randomization process for allocation to different groups (even with quasi-randomized studies), whether the numbers of participants in the intervention and control groups were provided, whether preintervention and postintervention data for each group were provided, whether losses to follow-up were reported and whether outcome reporting related to the study aims. ${ }^{\dagger}$ We also examined whether all outcomes were evaluated for all participants and whether adjustments for cluster sampling 


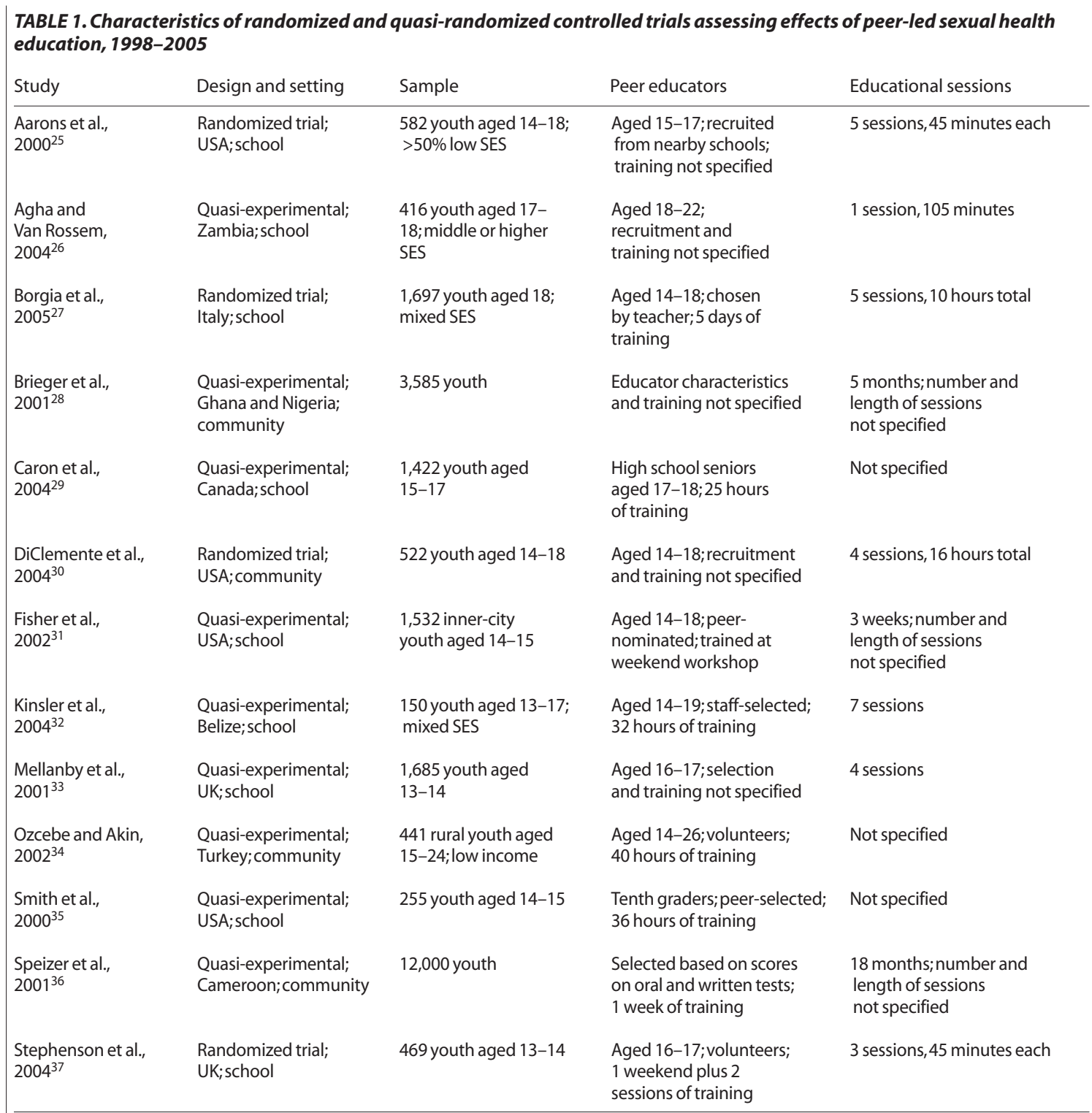

Notes: For inclusion, studies had to include a control or comparison group whose social and demographic characteristics were similar to those of the intervention group, provide preintervention data for all groups, provide postintervention data for all groups and report all outcomes. SES=socioeconomic status.

were made in clustered studies.

For the randomized controlled trials, we determined whether randomization and allocation concealment met the criteria of Jüni et al. ${ }^{22}$ Adequate approaches for randomization included use of a table of random numbers, coin tossing or computer generation of random numbers; inadequate strategies included systematic allocation, such as alternating the intervention assignment of clinic attenders. Allocation is generally considered adequately concealed if neither investigators nor subjects can foresee the latter's assignments; however, the nature of interventions reviewed here precluded the blinding of those providing or receiving interventions. Instead, we ascertained the blinding of the researchers who assessed outcomes. When necessary, we contacted authors for clarification of these and other study details.

We also assessed the extent to which Harden and col- leagues' recommendations for the development and evaluation of peer-led interventions were addressed in study reports. For intervention development, we determined whether adolescents' health needs and views were assessed in the initial phases of intervention development, whether young people took an active role in developing the intervention, whether subgroups of adolescents provided input, whether the research looked beyond individual change and took the community into account, and whether the authors provided a clear statement regarding working boundaries between the youth and adults.

Similarly, we examined whether the studies fulfilled Harden and colleagues' recommendations for the evaluation of peer-led interventions. Specifically, we assessed whether the study used both qualitative and quantitative methods, whether it provided details about how peer leaders were recruited and selected, whether young people's 
TABLE 2. Randomized and quasi-randomized controlled trials assessing effects of peer-led sexual health education, by adherence to Harden's recommendations on development of interventions

\begin{tabular}{|c|c|c|c|c|c|c|}
\hline Study & $\begin{array}{l}\text { Needs } \\
\text { assessment }\end{array}$ & $\begin{array}{l}\text { Youth input in } \\
\text { development }\end{array}$ & $\begin{array}{l}\text { Context of } \\
\text { youth's lives }\end{array}$ & $\begin{array}{l}\text { Part of wider } \\
\text { strategy }\end{array}$ & $\begin{array}{l}\text { Input from } \\
\text { subgroups }\end{array}$ & Boundaries \\
\hline Aarons et al. ${ }^{25}$ & Not & Yes & Yes & Yes & Yes & No \\
\hline Agha and Van Rossem 26 & Yes & No & $\mathrm{u}$ & Yes & No & $\mathrm{u}$ \\
\hline Borgia et al. ${ }^{27}$ & Yes & Yes & No & Yes & No & $\mathrm{u}$ \\
\hline Brieger et al. ${ }^{28}$ & No & Yes & Yes & Yes & No & Yes \\
\hline Caron et al. ${ }^{29}$ & $\mathrm{u}$ & No & No & Yes & No & No \\
\hline DiClemente et al. ${ }^{30}$ & Yes & Yes & Yes & Yes & No & $\mathrm{u}$ \\
\hline Fisher et al. ${ }^{31}$ & Yes & $\mathrm{u}$ & Yes & Yes & Yes & $\mathrm{u}$ \\
\hline Kinsler et al. ${ }^{32}$ & Yes & Yes & No & Yes & No & $\mathrm{u}$ \\
\hline Mellanby et al. ${ }^{33}$ & No & No & Yes & Yes & No & $\mathrm{u}$ \\
\hline Ozcebe and Akin 34 & No & No & $\mathrm{u}$ & Yes & Yes & $\mathrm{u}$ \\
\hline Smith et al. ${ }^{35}$ & Yes & Yes & Yes & Yes & No & $\mathrm{u}$ \\
\hline Speizer et al. ${ }^{36}$ & No & No & $\mathrm{u}$ & Yes & No & $\mathrm{u}$ \\
\hline Stephenson et al. ${ }^{37}$ & Yes & Yes & Yes & Yes & Yes & No \\
\hline
\end{tabular}

views were prioritized, whether the applicability of the peer-led method to the study population was critically examined, whether the relative contribution of the intervention to a broader health promotion strategy was explored, whether reciprocal peer education and the intervention's effects on peer leaders were examined, whether the quantitative and qualitative work were integrated and whether researchers engaged in skills sharing (e.g., whether those working on outcome evaluations used data from process evaluations to explain findings).

\section{Other Analyses}

We performed a narrative analysis, describing studies according to the use, training and recruitment of peers, composition of target population, intervention site, intervention components, theoretical basis and outcome findings. We used random effects meta-analysis to estimate pooled effects when four or more studies used the same outcome measure; odds ratios were calculated using results from final follow-up. For cluster randomized controlled trials that did not provide an intraclass correlation coefficient (a measure of consistency for a data set that has multiple groups), the results were adjusted using a conservative value of 0.05 for rho. Analyses were conducted using STATA 9 and Review Manager 4.2.

We examined heterogeneity by using the $\mathrm{I}^{2}$ test for consistency (an $\mathrm{I}^{2}$ value of 0.75 or greater indicates that variability across studies is due to heterogeneity rather than chance). ${ }^{23}$ We explored the effect of methodological diversity on heterogeneity (i.e., variance of the studies between methodological quality and Harden's methodological and reporting recommendations, such as setting,

*Smaller studies provide less precision and have larger standard errors than bigger studies do. Therefore, plotting the standard error of the log odds ratio against the reported log odds ratio tends to yield widely scattered points for smaller studies, and points close to the plot's midline for larger studies. In the absence of bias, the resulting plot may look like a symmetrical inverted funnel. Possible causes of asymmetrical funnel plots include not only publication bias but also poor methodological quality in smaller studies, true heterogeneity, artifacts and chance (source:Tang J and Liu JL, Misleading funnel plot for detection of bias in meta-analysis, Journal of Clinical Epidemiology, 2000,53(5):477-484). session lengths and peer responsibilities). ${ }^{14}$ Finally, to examine effects of smaller studies and explore the possible presence of publication bias, we created a funnel plot. ${ }^{* 14,24}$

\section{RESULTS}

\section{Search Results}

The combined searches yielded 4,500 electronic records. We screened these records for eligibility and obtained 33 articles for further assessment. Thirteen of the 33 articles met all four core methodological inclusion criteria and were included in the review; ${ }^{25-37}$ nine were quasi-experimental and four were randomized controlled trials (Table 1, page 91). Modes of evaluation were questionnaire, interview, survey and (in the studies testing for STIs) vaginal swab testing (not shown). Eight of the studies were conducted in developed countries, mainly the United Kingdom and the United States, and three of the five remaining studies were set in Africa. Nine studies were conducted in school settings and four were community based (e.g., health center).

Peer leaders ranged in age from 14 to 26 . Several studies tried to balance the proportion of male and female peer educators, but those that relied on volunteer peer educators tended to have more females than males (not shown).

\section{Methodological Quality}

Only three studies met all 10 of the quality criteria. ${ }^{30,31,37}$ Two met nine criteria, in both cases failing to provide an intraclass correlation coefficient. ${ }^{34,35}$ Two studies did not provide a clear definition of aims, ${ }^{25,29}$ and two lacked sufficient description of the study design and intervention to allow replication. ${ }^{27,36}$ Random allocation was noted in all but three trials. ${ }^{29,32,33}$ Ten studies evaluated all participants; the others assessed outcomes in a random sample. ${ }^{26,28,36}$ Three studies did not report attrition by group. ${ }^{28,32,36}$ All of the studies reported results for each outcome measure and provided the number of participants per condition as well as pre- and post-intervention data.

Cluster sampling was used in all 13 studies. Effects of cluster sampling were taken into account in seven studies: Three used intraclass correlation coefficients, ${ }^{27,32,33}$ while 


\begin{tabular}{|c|c|c|c|c|c|c|c|c|c|}
\hline Study & $\begin{array}{l}\text { Mixed } \\
\text { research } \\
\text { methods }\end{array}$ & $\begin{array}{l}\text { Recruitment/ } \\
\text { selection } \\
\text { described }\end{array}$ & $\begin{array}{l}\text { Effects of } \\
\text { being peer } \\
\text { educator }\end{array}$ & $\begin{array}{l}\text { Reciprocal } \\
\text { peer } \\
\text { education }\end{array}$ & $\begin{array}{l}\text { Prioritized } \\
\text { youth's } \\
\text { views }\end{array}$ & $\begin{array}{l}\text { Applicability } \\
\text { examined }\end{array}$ & $\begin{array}{l}\text { Contribution } \\
\text { to wider health } \\
\text { promotion }\end{array}$ & $\begin{array}{l}\text { Integrated } \\
\text { techniques }\end{array}$ & $\begin{array}{l}\text { Skills } \\
\text { sharing }\end{array}$ \\
\hline Aarons et al. ${ }^{25}$ & No & No & No & No & No & Yes & Yes & No & No \\
\hline Agha and Van Rossem ${ }^{26}$ & Yes & No & No & No & Yes & No & Yes & No & No \\
\hline Borgia et al. ${ }^{27}$ & Yes & Yes & No & No & $\mathrm{u}$ & No & Yes & Yes & No \\
\hline Brieger et al. ${ }^{28}$ & Yes & Not & No & No & Yes & Yes & Yes & Yes & No \\
\hline Caron et al. ${ }^{29}$ & No & No & Yes & No & No & No & Yes & No & No \\
\hline DiClemente et al. ${ }^{30}$ & Yes & No & No & No & $\mathrm{u}$ & Yes & Yes & Yes & No \\
\hline Fisher et al. ${ }^{31}$ & No & Yes & No & No & Yes & Yes & Yes & No & No \\
\hline Kinsler et al. ${ }^{32}$ & No & Yes & No & No & No & Yes & Yes & No & No \\
\hline Mellanby et al. ${ }^{33}$ & No & No & No & No & $\mathrm{u}$ & Yes & Yes & No & No \\
\hline Ozcebe and Akin ${ }^{34}$ & No & No & No & No & No & No & Yes & No & No \\
\hline Smith et al. ${ }^{35}$ & Yes & Yes & Yes & No & $\mathrm{u}$ & Yes & Yes & No & No \\
\hline Speizer et al. ${ }^{36}$ & No & Yes & Yesł & No & No & No & Yes & No & No \\
\hline Stephenson et al. ${ }^{37}$ & Yes & Yes & Yesł & No & Yes & Yes & Yes & Yes & No \\
\hline
\end{tabular}

the other four mentioned adjustment for clustering effects but did not provide the coefficient. ${ }^{29-31,37}$

Two of the four randomized controlled trials had adequate allocation sequence and concealment. ${ }^{30,37}$ The blinding of outcome assessors was not reported in any study.

\section{Development and Evaluation Criteria}

None of the studies fulfilled all of Harden and colleagues' recommendations for intervention development (Table 2, page 92). Seven reported assessing youth health needs and views, ${ }^{26,27,30-32,35,37}$ and the same number involved young people in the development process $25,27,28,30,32,35,37$ or took context into account. ${ }^{25,28,30,31,33,35,37}$ All of the studies reported targeting the individual as well as broader sociocultural or economic factors. Four studies sought input from subgroups of youth. ${ }^{25,31,34,37}$ Establishment of boundaries between peers, adults and research staff was described in only one study. ${ }^{28}$

Similarly, no study met all nine of Harden and colleagues' recommendations for evaluation of interventions (Table 3). Six studies used a mix of quantitative and qualitative methods, ${ }^{26-28,30,35,37}$ and an identical number detailed the peer recruitment and training process. $27,31,32,35-37$ Four studies referred to the effects of being a peer educator, ${ }^{29,35-37}$ though none examined reciprocal peer education. Four studies reported prioritizing the views of young people. ${ }^{26,28,31,37}$ Applicability of peer education to high-risk groups was discussed in eight studies. ${ }^{25,28,30-33,35,37}$ All of the studies discussed the relative contribution to community well-being that sexual health education would make. Four studies integrated quantitative and qualitative methods; $27,28,30,37$ none utilized skills sharing.

\section{Intervention Effects}

Eleven of the reviewed studies assessed contraceptive usage, in most cases condom usage; several also examined other behavioral outcomes. Some of the studies measured

*The odds ratios for condom use at last sex in the study by Aarons and colleagues were 3.39 (95\% confidence interval, 1.16-9.95) among females and 1.53 (0.55-4.26) among males. outcomes at multiple time points; we focused on results reported at final follow-up.

Eight studies measured condom use at last intercourse. For the cluster studies that did not provide an intraclass correlation coefficient, we adjusted the odds ratios reported by the authors. However, the report by Aarons and colleagues ${ }^{25}$ did not provide the number of participants of each gender; without that information, we could not adjust the odds ratio for clustering. ${ }^{*}$ For the remaining seven studies, the pooled odds of condom use at last intercourse were 1.1 (95\% confidence interval, 0.9-1.2). After adjustment for clustering, the effect estimate was 1.0 (Table 4). The $I^{2}$ value for these studies was $77 \%$ (not shown). The funnel plot for the data is nearly symmetrical (Figure 1, page 94); the symmetry would be more apparent if the plot included more data points. Nevertheless, the figure shows the larger studies (represented by the three leftmost points) falling close to the midline, while the smaller studies (the remaining points) are farther from the midline. This reveals that the small studies did not show a greater treatment effect than the larger, more precise studies.

The heterogeneity of studies did not fall below $75 \%$ when they were examined in subgroups according to methodological quality criteria or to most of Harden's criteria (not shown). The exception was for the subgroup of studies that had detailed the recruitment and selection

TABLE 4. Adjusted odds ratios (and 95\% confidence intervals) of condom use at last sex in randomized and quasirandomized controlled trials

\begin{tabular}{|c|c|c|}
\hline Study & $\begin{array}{l}\text { No. of } \\
\text { subjects }\end{array}$ & Odds ratio \\
\hline Agha and Van Rossem ${ }^{26}$ & 193 & $0.55(0.12-2.47)$ \\
\hline Borgia et al. ${ }^{27}$ & 653 & $1.03(0.78-1.36)$ \\
\hline Brieger et al. ${ }^{28}$ & 569 & $1.28(0.63-2.60)$ \\
\hline DiClemente et al. ${ }^{30}$ & 460 & $1.34(0.56-3.17)$ \\
\hline Smith et al. ${ }^{35}$ & 51 & $0.98(0.29-3.26)$ \\
\hline Speizer et al. ${ }^{36}$ & 816 & $0.99(0.54-1.80)$ \\
\hline Stephenson et al. ${ }^{37}$ & 2,112 & $1.00(0.60-1.67)$ \\
\hline All studies & & $1.04(0.85-1.28)$ \\
\hline
\end{tabular}

Note: Odds ratios are adjusted for cluster effects. 


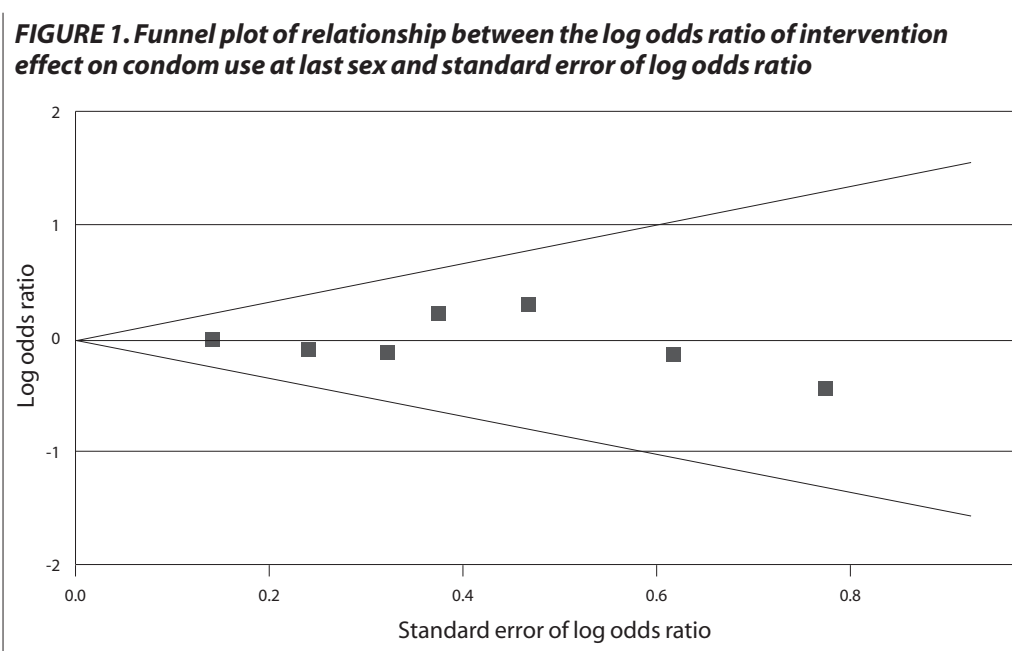

Note: From left to right: Borgia et al., ${ }^{27}$ Stephenson et al.. ${ }^{37}$ Speizer et al., ${ }^{36}$ Brieger et al., ${ }^{28}$ DiClemente et al., ${ }^{30}$ Smith et al. ${ }^{35}$ and Agha et al. ${ }^{26}$ filled all but one of the methodological criteria (blinding of the outcome assessors was not reported).

Most of the studies found positive effects on measures of knowledge, attitudes and intentions. These results should be viewed cautiously, however, as it was not always clear how many variables were measured and whether the length of time between intervention exposure and outcome assessment was consistent among all studies.

Another reason for caution is that the methodological quality of studies was generally poor. Only 13 of 33 potentially eligible studies fulfilled the four basic methodological inclusion criteria. Even among the studies included in the review, just three met all of Harden and colleagues' quality criteria. ${ }^{30,31,37}$ The low methodological quality suggests the potential for bias in the study results.

No study addressed all of Harden and colleagues' recommendations for the development and evaluation of peer-led sexual health interventions. Although nearly all of the studies examined the interventions' applicability to high-risk groups and their relative contribution to broader health strategies, each of the remaining criteria was met by fewer than half of the studies.

In general, the high level of heterogeneity across studies was not reduced by subgroup analysis according to quality criteria or fulfillment of Harden and colleagues' recommendations, perhaps because different sources of heterogeneity were acting in different directions. However, in the analysis by selection and recruitment process for peer educators, four studies showed homogeneity $\left(I^{2}=0\right) .{ }^{27,35-37}$ The peer recruitment methods used in these four studies varied, so it is not clear why the studies would be homogeneous. The finding could be a statistical artifact, and should be reassessed in future systematic reviews.

Our review had a number of limitations. In making adjustments for clustering, we used a conservative value of rho; however, this did not influence the main findings, as both the adjusted and unadjusted 95\% confidence intervals of the odds ratio for condom use at last sex included 1.0. Because of resource constraints, data in this review were extracted by only one reviewer; use of a second reviewer would have reduced the risk of error and subjectivity. Most authors did not respond to requests for missing information, and therefore the review reflects the information provided in published reports; the degree to which these reports correspond to how the studies were conducted cannot be ascertained. The assessment of whether studies addressed Harden and colleagues' recommendations was inevitably subjective for some factors and represents a limitation in using these recommendations to evaluate peer-led sexual health interventions. Only published studies were reviewed, which could bias the results toward interventions that have shown changes in outcome. Finally, there were insufficient studies using the same outcome measures to use regression to robustly assess the impact of study quality and bias, intervention components or adherence to Harden's recommendations on efficacy. 


\section{Implications and Recommendations}

Fulfillment of the four core methodological criteria should be a standard in future research and program development. Although the randomized controlled trial design, which can show a causal association, is the "most rigorous way to evaluate the effectiveness of an intervention," 38 it is vital that such trials be of high methodological quality. Cluster sampling calculations should be part of the trial design, and analysis should demonstrate similarity among the groups assessed.

Harden and colleagues' recommendations emerged from an analysis of the key issues, problems and gaps in peer-led interventions and their evaluation. Authors should address these recommendations or explain why they have not done so. For example, assessment of youth health needs and views would be a rational and essential component of the initial phase of project development, as identifying youths' needs would help in determining whether peer delivery is an appropriate method. Yet only half of the studies in this review assessed youth health needs and views. Similarly, only a few studies have evaluated how interventions affect peer leaders. ${ }^{39,40}$

Although we focused on outcome evaluations in this review, process evaluations are also important. Process evaluations can assess the full impact of interventions on adolescents and peer leaders, ${ }^{38}$ and can be instrumental in developing these programs by ascertaining youth health needs and views. Process and outcome evaluations are complementary and should be implemented in all evaluations in order to attain a full overview of a program's effects.

Finally, although most of the studies examined in this review did not find unambiguous support for peer-led interventions, we believe that this approach should not be abandoned but rather fine-tuned. Because the peer-led approach seemed to hold so much promise, interventions were sometimes designed without much thought to the details. Given that the jump from theory to practice was not quite successful, researchers should look back on the shortcomings of prior studies, and place greater emphasis on details of intervention design, when creating, implementing and evaluating future peer-led programs.

\section{REFERENCES}

1. McCauley AP and Salter C, Meeting the needs of young adults, Population Reports, 1995, Series J, No. 41.

2. Weiss E, Whelan D and Gupta GR, Vulnerability and Opportunity: Adolescents and HIV/AIDS in the Developing World, Washington, DC: International Center for Research on Women, 1996.

3. Darroch JE, Singh S and Frost JJ, Differences in teenage pregnancy rates among five developed countries: the roles of sexual activity and contraceptive use, Family Planning Perspectives, 2001, 33(6):244-250 $\& 281$

4. National Health Service Centre for Reviews and Dissemination, Preventing and reducing the adverse effects of unintended teenage pregnancies, Effective Health Care, 1997, Vol. 3, No. 1.

5. Sciacca JP, Student peer health education: a powerful yet inexpensive helping strategy, Peer Facilitator Quarterly, 1987, 5(2):4-6.

6. World Health Organization (WHO), United Nations Population Fund and United Nations Children's Fund, Action for Adolescent
Health: Towards a Common Agenda, Geneva: WHO, 1997.

7. Shiner M, Defining peer education, Journal of Adolescence, 1999, 22(4):555-566.

8. Bandura A, Social Learning Theory, Englewood Cliffs, NJ, USA: Prentice-Hall, 1977.

9. Turner G and Shepherd J, A method in search of a theory: peer education and health promotion, Health Education Research, 1999, 14(2): $235-247$.

10. Svenson GR, European Guidelines for Youth AIDS Peer Education, Malmö, Sweden: European Commission, 1998.

11. Oakley A et al., Sexual health education interventions for young people: a methodological review, BMJ, 1995, 310(6973):158-162.

12. Peersman Get al., Review of Effectiveness of Sexual Health Promotion Interventions for Young People, London: Social Science Research Unit, Institute of Education, University of London, 1996.

13. Harden A, Weston R and Oakley A, A Review of the Effectiveness and Appropriateness of Peer-Delivered Health Promotion Interventions for Young People, London: Social Science Research Unit, Institute of Education, University of London, 1999.

14. Alderson P, Green S and Higgins JPT, eds., Cochrane Reviewers' Handbook 4.2.2, UK: John Wiley \& Sons, 2004.

15. EPPI-Centre, EPPI-Centre Methods for Conducting Systematic Reviews, London: Social Science Research Unit, Institute of Education, University of London, 2007.

16. Pandey GK et al., Interventions to modify sexual risk behaviors for preventing HIV infection in street children and youth people in developing countries (protocol), Cochrane Database of Systematic Reviews, 2005, Issue 4, No. CD 005480.

17. Ehiri JE, Meremikwu A and Meremikwu M, Interventions for preventing unintended pregnancies among adolescents (protocol), Cochrane Database of Systematic Reviews, 2005, Issue 2, No. CD 005215.

18. Wise J, MRC issues guidelines for clinical trials, BMJ, 1998, 316(7135):881.

19. WHO European Working Group on Health Promotion Evaluation, Health Promotion Evaluation: Recommendations to Policymakers, Copenhagen, Denmark: WHO, 1998.

20. Howard M and McCabe JB, Helping teenagers postpone sexual involvement, Family Planning Perspectives, 1990, 22(1):21-26.

21. Zaslow MJ and Takanishi R, Priorities for research on adolescent development, American Psychologist, 1993, 48(2):185-192.

22. Jüni $P$, Altman DG and Egger M, Assessing the quality of controlled clinical trials, BMJ, 2001, 323(7303):42-46.

23. Higgins JP et al., Measuring inconsistency in meta-analyses, BMJ, 2003, 327(7414):557-560.

24. Sterne JAC, Egger M and Smith GD, Investigating and dealing with publication and other biases in meta-analysis, BMJ, 2001, 323(7304): 101-105.

25. Aarons SJ et al., Postponing sexual intercourse among urban junior high school students-a randomized controlled evaluation, Journal of Adolescent Health, 2000, 27(4):236-247.

26. Agha S and Van Rossem R, Impact of a school-based peer sexual health intervention on normative beliefs, risk perceptions, and sexual behavior of Zambian adolescents, Journal of Adolescent Health, 2004, 34(5):441-452.

27. Borgia P et al., Is peer education the best approach for HIV prevention in schools? findings from a randomized controlled trial, Journal of Adolescent Health, 2005, 36(6):508-516.

28. Brieger WR et al., West African Youth Initiative: outcome of a reproductive health education program, Journal of Adolescent Health, 2001, 29(6):436-446.

29. Caron F et al., Evaluation of a theoretically based AIDS/STD peer education program on postponing sexual intercourse and on condom use among adolescents attending high school, Health Education Research, 2004, 19(2):185-197. 
30. DiClemente RJ et al., Efficacy of an HIV prevention intervention for African American adolescent girls: a randomized controlled trial, Journal of the American Medical Association, 2004, 292(2):171-179.

31. Fisher JD et al., Information-motivation-behavioral skills modelbased HIV risk behavior change intervention for inner-city high school youth, Health Psychology, 2002, 21(2):177-186.

32. Kinsler J et al., Evaluation of a school-based intervention for HIV/AIDS prevention among Belizean adolescents, Health Education Research, 2004, 19(6):730-738

33. Mellanby AR et al., A comparative study of peer-led and adult-led school sex education, Health Education Research, 2001, 16(4):481-492.

34. Ozcebe $\mathrm{H}$ and Akin L, Peer education approach to young people on reproductive health as an example from rural area, Turkey, Turkish Journal of Population Studies, 2002, 24(1):51-64.

35. Smith MU et al., Students Together Against Negative Decisions (STAND): evaluation of a school-based sexual risk reduction intervention in the rural South, AIDS Education and Prevention, 2000, 12(1):49-70

36. Speizer IS, Tambashe BO and Tegang SP, An evaluation of the "Entre Nous Jeunes" peer-educator program for adolescents in Cameroon, Studies in Family Planning, 2001, 32(4):339-351.

37. Stephenson JM et al., Pupil-led sex education in England (RIPPLE study): cluster-randomised intervention trial, Lancet, 2004, 364(9431): 338-346.

38. Oakley A et al., Process evaluation in randomised controlled trials of complex interventions, BMJ, 2006, 332(7538):413-416.

39. Backett-Milburn K and Wilson S, Understanding peer education: insights from a process evaluation, Health Education Research, 2000, 15(1) 85-96.

40. Ebreo A et al., Effects of peer education on the peer educators in a school-based HIV prevention program: where should peer education research go from here? Health Education \& Behavior, 2002, 29(4):411- 423.

\section{RESUMEN}

Contexto: Las intervenciones conducidas por pares se han convertido en un método popular en la educación sexual a adolescentes, pero la eficacia de este enfoque y la calidad metodológica de ensayos recientes no han sido revisadas de manera sistemática.

Métodos: Se condujo una serie de búsquedas electrónicas y manuales para identificar los ensayos controlados quasialeatorios y aleatorios de actividades de educación en salud publicados de 1998 a 2005. Los estudios fueron elegibles si tenían un grupo de comparación apropiado; si proporcionaban datos de pre-y post-intervención; y si reportaron todos los resultados. Se hizo un resumen de los resultados del estudio y, cuando fue apropiado, se los combinaron; adicionalmente, se hizo una evaluación de 10 aspectos de la calidad metodológica de los estudios.

Resultados: Trece artículos cumplieron con los criterios de inclusión. Los resultados combinados y ajustados de siete ensayos que examinaron los efectos de intervenciones conducidas por pares sobre el uso del condón en la última relación sexual no encontraron algún beneficio (razón de momios, 1.0). Ninguno de los tres ensayos que evaluaron el uso consistente del condón encontró un beneficio. Un estudio reportó una reducción de riesgo de clamidia (0.2), pero otro no encontró impacto en la incidencia de ITS. Un estudio encontró que las mujeres jóvenes (pero no los hombres jóvenes) que recibieron educación conducida por pares tuvieron menor probabilidad que las que no la recibieron de haber tenido alguna vez relaciones sexuales. La mayoría de las intervenciones produjo mejoras en conocimientos, actitudes e intenciones. Solamente tres estudios cumplieron con los 10 criterios de calidad evaluados; otros dos cumplieron con nueve criterios.

Conclusiones: A pesar de los resultados promisorios en algunos ensayos, los hallazgos generales no proporcionan evidencia convincente de que la educación conducida por pares mejore los indicadores de salud sexual en adolescentes. Futuros ensayos deben basarse en los ensayos exitosos conducidos a la fecha y deben tratar de cumplir con los criterios de calidad existentes.

\section{RÉSUMÉ}

Contexte: Les interventions menées par les pairs représentent aujourd'hui une méthode prisée d'apport de prestations d'éducation à la santé sexuelle aux adolescents. L'efficacité de l'approche et la qualité méthodologique d'essais récents n'ont cependant pas fait l'objet d'un examen systématique.

Méthodes: Des recherches électroniques et manuelles ont été effectuées pour identifier les essais comparatifs quasi-aléatoires et aléatoires d'éducation par les pairs à la santé sexuelle des adolescents publiés de 1998 à 2005. Les études admises devaient comporter un groupe témoin approprié, présenter des données pré-et post-intervention et rapporter toutes les issues. Les résultats de l'étude ont été résumés et, dans la mesure où il convenait de le faire, groupés; 10 aspects de qualité méthodologique des études ont aussi été évalués.

Résultats: Treize articles se sont avérés conformes aux critères d'inclusion. Les résultats ajustés groupés de sept essais portant sur les effets d'interventions menées par les pairs sur l'usage du préservatif lors des derniers rapports sexuels n’ont révélé aucun avantage global (rapport de probabilités, 1,0). Aucun des trois essais d'évaluation d'usage constant du préservatif n'a révélé d'avantage. Une étude a signalé un risque réduit de chlamydia $(0,2)$, mais une autre n'a constaté aucun effet sur l'incidence des IST. Une étude a conclu que les jeunes femmes (mais pas les jeunes hommes) qui avaient reçu une éducation menée par leurs pairs étaient moins susceptibles d'avoir jamais eu de rapports sexuels. La plupart des interventions ont produit une amélioration de la connaissance, des attitudes et des intentions. Trois études seulement ont satisfait aux 10 critères de qualité évalués; deux autres ont satisfait à neuf.

Conclusions: Malgré les résultats prometteurs de certains essais, les résultats globaux n'apportent pas d'indices convaincants quant aux effets bénéfiques de l'éducation par les pairs sur les issues sexuelles des adolescents. Les essais à venir devront renforcer les succès remportés à ce jour tout en cherchant à satisfaire aux critères de qualité existants.

\section{Acknowledgments}

The authors greatly appreciate the invaluable help of Angela Harden, Helen Weiss and Mazeda Hossain.

Author contact:caron.kim@aya.yale.edu 